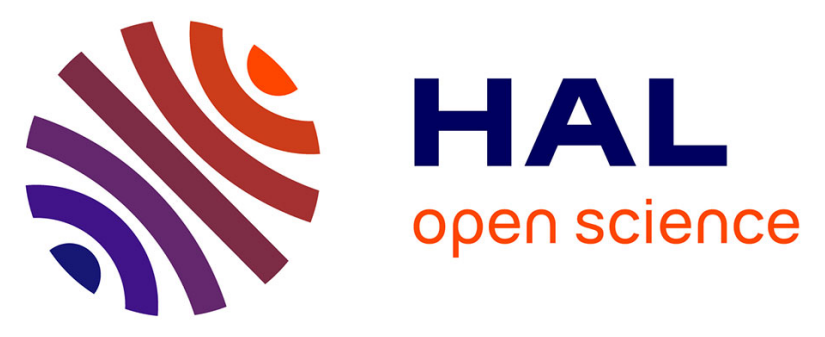

\title{
Highly Efficient Thermally Activated Delayed Fluorescence via an Unconjugated Donor-Acceptor System Realizing EQE of Over $30 \%$
}

Chen-chen Peng, Sheng-Yi Yang, Hong-cheng Li, Guo-hua Xie, Lin-song Cui, Sheng-nan Zou, Cyril Poriel, Zuo-quan Jiang, Liang-sheng Liao

\section{To cite this version:}

Chen-chen Peng, Sheng-Yi Yang, Hong-cheng Li, Guo-hua Xie, Lin-song Cui, et al.. Highly Efficient Thermally Activated Delayed Fluorescence via an Unconjugated Donor-Acceptor System Realizing EQE of Over 30\%. Advanced Materials, 2020, 32 (48), pp.2003885. 10.1002/adma.202003885 . hal02997314

HAL Id: hal-02997314

https://hal-univ-rennes1.archives-ouvertes.fr/hal-02997314

Submitted on 11 Nov 2020

HAL is a multi-disciplinary open access archive for the deposit and dissemination of scientific research documents, whether they are published or not. The documents may come from teaching and research institutions in France or abroad, or from public or private research centers.
L'archive ouverte pluridisciplinaire HAL, est destinée au dépôt et à la diffusion de documents scientifiques de niveau recherche, publiés ou non, émanant des établissements d'enseignement et de recherche français ou étrangers, des laboratoires publics ou privés. 


\section{WILEY-VCH}

DOI: $10.1002 /($ adma.202003885)

Article type: Communication

Highly Efficient Thermally Activated Delayed Fluorescence via Unconjugated DonorAcceptor System Realizing EQE of over 30\%

Chen-Chen Peng, Sheng-Yi Yang, Hong-Cheng Li, Guo-Hua Xie, Lin-Song Cui, Sheng-Nan Zou, Cyril Poriel, Zuo-Quan Jiang*, and Liang-Sheng Liao*

C.-C. Peng, S.-Y. Yang, H.-C. Li, S.-N. Zou, Prof. Z.-Q. Jiang, Prof. L.-S. Liao

Institute of Functional Nano \& Soft Materials (FUNSOM), Jiangsu Key Laboratory for Carbon-Based Functional Materials \& Devices, Joint International Research Laboratory of Carbon-Based Functional Materials and Devices, Soochow University, Suzhou, Jiangsu 215123, China.

Dr. G.-H. Xie

Hubei Key Lab on Organic and Polymeric Optoelectronic Materials, Department of Chemistry, Wuhan University, Wuhan 430072, People's Republic of China.

Prof. C. Poriel

Univ Rennes, CNRS, ISCR- UMR 6226, 35000 Rennes, France.

Dr. L.-S. Cui

Cavendish Laboratory, University of Cambridge, JJ Thomson Avenue, Cambridge, CB3 OHE, United Kingdom.

Prof. L.-S. Liao

Institute of Organic Optoelectronics, Jiangsu Industrial Technology Research Institute (JITRI), Wujiang, Suzhou, Jiangsu 215211, China

E-mail: Prof. Z.-Q. Jiang: zqjiang@suda.edu.cn; Prof. L.-S. Liao: Isliao@suda.edu.cn.

Keywords: thermally activated delayed fluorescence, organic light-emitting diodes, high efficiency, intramolecular spatial charge transfer, unconjugated system

Here, two novel thermally activated delayed fluorescence (TADF) emitters, 2tDMG and 3tDMG, were synthesized for high-efficiency organic light-emitting diodes (OLEDs), The two emitters have a tilted face-to-face alignment of donor (D)/acceptor (A) units presenting intramolecular non-covalent interactions. The two TADF materials were deposited either by evaporation-process or by solution-process, both of them leading to high OLEDs performance. 2tDMG used as the emitter in an evaporation-processed OLEDs achieves a high external 


\section{WILEY-VCH}

quantum efficiency (EQE) of $30.8 \%$ with a very flat efficiency roll-off of $7 \%$ at $1000 \mathrm{~cd} / \mathrm{m}^{2}$. The solution-processed OLEDs also displays an interesting EQE of 16.2\%. 3tDMG shows improved solubility and solution processability as compared to 2tDMG, and thus a high EQE of $20.2 \%$ in solution-processed OLEDs is recorded. The corresponding evaporation-processed OLEDs also reach a reasonably high EQE of $26.3 \%$. Encouragingly, this work provides a novel strategy to address the imperious demands for OLEDs with high EQE and low roll-off.

In the past decade, the development of organic light-emitting diodes (OLEDs) was reshaped by thermally activated delayed fluorescence (TADF) which can fully utilize both singlet/triplet manifold excitons through reverse intersystem crossing (RISC) and remove heavy metal by using environmentally benign pure organic molecules. ${ }^{[1]}$ Now, the cuttingedge TADF materials can exceed $30 \%$ external quantum efficiency (EQE) in electroluminescent devices, but these highly efficient TADF materials are basically limited to donor (D)- $\pi$-acceptor (A) molecular architecture. ${ }^{[2]}$ This type of molecular design, firstly proposed by Adachi et al. for TADF, ${ }^{[1 \mathrm{a}]}$ can tune their $\mathrm{D}$ or/and A groups, geometries and steric hindrance between them to generate twisted induced charge-transfer (TICT)-type emission. ${ }^{[3]}$ The twisted dihedral angle between D and A units can minimize the singlet-triplet splitting energy $\left(\Delta E_{\mathrm{ST}}\right)$ for fast RISC, ${ }^{[1 \mathrm{c}, 4]}$ but the resulted TADF OLEDs still need to be significantly improved, notably in terms of efficiency roll-off at high brightness and concentration quenching because of the $\pi-\pi$ intermolecular interactions in the solid-state. ${ }^{[5]}$ Another way to achieve TADF is to use D/A complex, in which the D/A blocks are spatially isolated, but their forming exciplexes are far less efficient than D- $\pi-\mathrm{A}$ analogues and the resulting OLEDs also display severe efficiency roll-off. ${ }^{[6]}$

Recently, researchers conceptually consider that the intramolecular noncovalent interaction between D/A units in face-to-face alignment could be a new option to realize TADF. ${ }^{[7]}$ 


\section{WILEY-VCH}

Constructing TADF materials in this unconjugated way has the potential to combine the small $\Delta E_{\mathrm{ST}}$ value with substantial transition dipole and achieve high luminescent efficiency. ${ }^{[8]}$ These two electron-rich and electron-poor $\pi$-systems need to be held close in space to form homoconjugation. In this regard, dozens of molecular frameworks have been employed but the performances remain around 10\% 20\% EQE, ${ }^{[7,8]}$ similar to those of D/A complexes. The problem may probably account for the D/A geometry not only the D/A distance. In other words, short D/A distance is essential for TADF but cannot ensure high efficiency which is more challenged and determinant for material and device performance. In addition, restriction of intramolecular motion (RIM) should also be taken into account in regard to enhancing photoluminescence quantum yield (PLQY). ${ }^{[\mathrm{b}, 5,7 \mathrm{~b}, 9]}$ However, in previously reported structures, it is noted that both D and A units are extended in single bonds, indicating the molecular conrotatory motion cannot be thoroughly restricted..$^{[4,7 c, 7 \mathrm{~d}]}$ Even though these D/A units exist in a short distance and the excitation process is completed, the emission energy may be lost in free rotation.

In this work, we designed highly efficient TADF materials based on D/A intramolecular noncovalent interaction; the key design rules include not only the short D/A distance but also the fixation of the D/A geometry. We connected the D/A units via a rigid linker, thereby confining them into a closely-packed coplanar configuration (Figure 1a). ${ }^{[10]}$ In light of the molecular construction, the target TADF materials could achieve very small $\Delta E_{\mathrm{ST}}$ and high PLQY simultaneously. Besides, we also introduced $t$-butyl groups to improve the solubility of the TADF emitters. For the acceptor, the 2,4,6-triphenyl-1,3,5-triazine (TPZ) is a nearly planar structure because of strong hydrogen bonding, and the rigid structure contributes to space charge transfer and reduced molecular vibration leads to enhanced PLQY. Two greenish-blue TADF emitters, 2-(tert-butyl)-10-(4-(tert-butyl)phenyl)-1'-(4-(4,6-diphenyl1,3,5-triazin-2-yl)phenyl)-10H-spiro[acridine-9,9'-fluorene] (2tDMG) and 2,7-di-tert-butyl- 


\section{WILEY-VCH}

10-(4-(tert-butyl)phenyl)-1'-(4-(4,6-diphenyl-1,3,5-triazin-2-yl)phenyl)-10H-spiro[acridine-

9,9'-fluorene] (3tDMG), were applied in both evaporation-processed and solution-processed TADF OLEDs. 2tDMG achieved an extremely high EQE of 30.8\% (evaporation-process) with efficiency roll-off while 3tDMG also obtained a high EQE of 20.2\% (solution-process) because of its better solubility. These excellent results open new avenues for the study of spatial electronic interactions in organic emissive materials.

The TADF materials of 2tDMG and 3tDMG can be facilely prepared through efficient threestep reactions (Supporting Information, Scheme S1). Although the overall yield of the optimized route is high, it should be noted that the reaction sequence is quite critical. We once tried to append the donor, the $t$-butyl substituted triphenylamine, at C9 site of fluorene to form spiro structure and then linked it with the acceptor, TPZ, to afford the target molecules. But due to the great steric hindrance at $\mathrm{C} 1$ site of fluorene,${ }^{[11]}$ the last-step Pd-catalyzed coupling gave no product. The synthetic failure is an important hint: in previous reports,${ }^{[12]}$ the researchers had not met similar difficulty when they introduced D/A units in short spatial distance via coupling reaction, indicating other molecular backbones to hold close D/A units were still somewhat flexible. But in our cases, the bulky and robust spiro-backbone prevented coupling reaction from happening at the adjacent $\mathrm{C} 1$ site.

The conjecture about D/A special conformation hinted by the above steric hindrance is confirmed by the single crystal structures of 2tDMG and 3tDMG (Supporting Information, Figure S1-S3, Table S1). Significantly, the presence of rigid spiro structure fixes the donor and refrains the acceptor from rotational and vibrational movement to a large extent. It indicates a short distance between donor and acceptor and a well D/A cofacial conformation, which are beneficial for spatial D/A charge transfer. ${ }^{[7 b, 13]}$ The minimum distances between A and the best fit plane of D are $3.09 \AA$ of 2tDMG and $3.11 \AA$ of 3tDMG which are similar to 


\section{WILEY-VCH}

the inter-ring distance $(3.09 \AA)$ of [2.2]paracyclophane, ${ }^{[14]}$ the closest stacked aromatic rings reported to date. Then, dihedral angles between the planes of the fluorene and the TPZ are $72.48^{\circ}$ and $69.57^{\circ}$ for 2tDMG and 3tDMG, respectively, indicating D/A planes in 2tDMG are in more parallel conformation.

Following the fascinating cofacial D/A configuration seen in the crystal structure, the D/A interaction was further understood by the computational simulation. Ground-state and excitedstate geometries at the B3LYP-D3BJ ${ }^{[15,16]} / \mathrm{def} 2-$ SVP $^{[17,18]}$ and $\mathrm{wb} 97 \mathrm{xd}^{[19]} / \mathrm{def} 2-\mathrm{SVP}^{[17,18]}$ levels are respectively performed (Supporting Information, Figure S4, Table S2). In lowlying singlet $\left(\mathrm{S}_{1}\right)$ state, the hole/electron are separated to the donor and acceptor respectively, but in low-lying triplet $\left(\mathrm{T}_{1}\right)$ state, the hole/electron are localized on the fluorene linker, because the fluorene segment has the lowest triplet energy (Supporting Information, Figure S5). The calculation also shows a significant separation of the highest occupied molecular orbitals (HOMOs) and the lowest unoccupied molecular orbitals (LUMOs). For both 2tDMG and 3tDMG, the HOMO is mainly located on the $t$-butyl substituted triphenylamine units and the LUMO is mostly situated at TPZ segments (Figure 1b, c). Because of the similar acceptor, 2tDMG and 3tDMG have similar LUMO energy levels of -2.091 and $-2.093 \mathrm{eV}$, respectively. Meanwhile, 3tDMG has a relatively higher HOMO (-4.896 eV) than 2tDMG $(-4.968 \mathrm{eV})$ owing to the stronger donor ability of the triphenylamine unit with one more $t$-butyl group. The detailed information is collected in Table S2. On the other side, the functions of reduced density gradient (RDG) and Sign $\left(\lambda_{2}\right) \rho$ were calculated to show the intramolecular noncovalent interactions in 2tDMG (Figure 1d, f) and 3tDMG (Figure 1e, g). The green region and brown region of RDG analysis show the presence of obvious attractive interactions and large steric hindrance between D and A moieties respectively, which could be beneficial for suppressing the intramolecular vibrations and reducing energy loss of the excited molecules. $^{[20]}$ 


\section{WILEY-VCH}

2tDMG and 3tDMG were analyzed by ultraviolet-visible (UV-vis) absorption and photoluminescence (PL) measurements in the toluene solution (Figure 2a). In the absorption spectra, 2tDMG and 3tDMG both show strong absorption at nearly $300 \mathrm{~nm}$ attributed to the local $\pi-\pi *$ transitions. On the other hand, they also exhibited an intramolecular charge transfer (ICT) transition band around $400 \mathrm{~nm}$ displaying weak absorption between 370 and $440 \mathrm{~nm}$, indicating a non-trivial level of interaction between the D/A moieties. Then, based on the absorption edges, the corresponding optical bandgaps can be calculated to be $2.75 \mathrm{eV}$ for 2tDMG, and $2.66 \mathrm{eV}$ for 3tDMG, respectively. When excited at $340 \mathrm{~nm}$ in the toluene solution at room temperature, a strong emission is observed for both 2tDMG and 3tDMG, at 502 and $505 \mathrm{~nm}$ respectively. We can obtain the $S_{1}$ energies and the $T_{1}$ energies of 2tDMG and 3tDMG from the fluorescence spectra and phosphorescent spectra in toluene at $77 \mathrm{~K}$ (Supporting Information, Figure S6). Therefore, the $\Delta E_{\mathrm{ST}} \mathrm{S}$ of 2tDMG and 3tDMG were calculated to be 0.03 and $0.01 \mathrm{eV}$, respectively. The $\Delta E_{\mathrm{STs}}$ are quite small and would be beneficial for the efficient RISC process. Figure $\mathbf{2 b}$ shows transient PL decay curves which were measured by vacuum-deposited process. Transient PL measurements of 2tDMG and 3tDMG dispersed in bis[2-(diphenylphosphino)phenyl]ether oxide (DPEPO) host material were investigated to analyze the excited-state lifetime for the delayed PL emission. The doped films exhibited a prompt decay component and a delayed emission decay profile. The prompt decays of 2tDMG and 3tDMG doped film with lifetimes of 106 and 91 ns are observed respectively, meanwhile, the delayed sections of these two TADF materials are respectively 3.43 and $2.28 \mu$ s measured at $300 \mathrm{~K}$. With the temperature decreasing from 300 to $100 \mathrm{~K}$, the delayed sections were reduced gradually. Because the delayed fluorescence emission process is triggered by RISC of TADF materials which is a thermally activated process, it reaffirms the TADF nature of 2tDMG and 3tDMG. To further compare exciton utilization, PLQY was 


\section{WILEY-VCH}

measured under nitrogen atmosphere and the PLQY of 2tDMG: DPEPO film (87\%) is slightly higher than 3tDMG: DPEPO film (86\%) (Supporting Information, Table S3).

The HOMO energy levels of 2tDMG and 3tDMG are determined by the onset of the first oxidation wave (Supporting Information, Figure S7), and the LUMO energy level can be calculated from the optical bandgap based on UV-vis absorption spectra and the HOMO energy level. The HOMO energy level of 2tDMG is estimated to be $-5.12 \mathrm{eV}$, and 3tDMG has a higher HOMO of $-5.03 \mathrm{eV}$ corresponding to the more $t$-butyl groups. For comparison, the spirophenylacridine-fluorene compound, not bearing $t$-butyl groups displays a lower HOMO energy level (-5.33 eV obtained from $\left.E^{1 / 2}\right) .{ }^{[21]}$ This translates the significant impact of the number of $t$-butyl groups located at the donor for HOMO energy level. The LUMO energy levels of 2tDMG and 3tDMG are both estimated to be $-2.37 \mathrm{eV}$ as their acceptor is identical. Therefore, the electrochemical bandgaps $\left(E_{\mathrm{g}} \mathrm{s}\right)$ of 2tDMG and 3tDMG are calculated to be 2.75 and $2.66 \mathrm{eV}$, respectively.

Thermal and morphological stabilities are fundamental to the fabrication and operation of OLED. To investigate the thermal stability, thermogravimetric analysis (TGA) was carried out under a nitrogen atmosphere. As presented in Figure S8, the decomposition temperatures $\left(T_{\mathrm{d}}\right)$ of 2tDMG and 3tDMG with 5\% weight loss are recorded at 369 and $375{ }^{\circ} \mathrm{C}$, respectively. Diff erential scanning calorimetry (DSC) of 2tDMG and 3tDMG have also been measured showing high glass transition temperatures of 165 and $154{ }^{\circ} \mathrm{C}$, respectively (Supporting Information, Figure S9). The results of TGA and DSC suggest that these two TADF materials can be fabricated in vacuum deposition and solution process for OLED manufacture because of great morphological stability. All these energy levels and physical properties are summarized in Table $\mathbf{1 .}$ 


\section{WILEY-VCH}

To investigate the electroluminescence (EL) properties of 2tDMG and 3tDMG, we fabricated the devices using these materials as emitters (Device 1-6). The OLED devices based on DPEPO as the host material exhibited a high efficiency at driving voltages lower than $3 \mathrm{~V}$, (Figure S10-S15). There is a trend that the operating voltages decrease as the doping ratios increase, implying charge-carrier transport property of TADF emitters is better than that of the DPEPO host material. Then, we added the hole and exciton blocking layers and fabricated device 1 (2tDMG) and 2 (3tDMG). The optimal device performance achieved with this structure of: ITO/ 1,4,5,8,9,11-hexaazatriphenylenehexacarbonitrile (HAT-CN, $10 \mathrm{~nm}$ )/ 1,1bis[(di-4-tolylamino)phenyl]cyclohexane (TAPC, 40 nm)/ 4,4',4',-tris-(carbazol-9-yl)triphenylamine (TCTA, $8 \mathrm{~nm}) /$ 1,3-di(9H-carbazol-9-yl)benzene $(m \mathrm{CP}, 8 \mathrm{~nm}) /$ DPEPO: 40 wt\% emitters $(20 \mathrm{~nm}) /$ DPEPO $(8 \mathrm{~nm}) /$ 1,3,5-tri[(3-pyridyl)-phen-3-yl]benzene (TmPyPB, 40 $\mathrm{nm}) /$ 8-hydroxyquinolinolato-lithium (Liq, $2 \mathrm{~nm}) / \mathrm{Al}(100 \mathrm{~nm})$. The device configuration and molecular structures of functional materials are shown in Figure S10. HAT-CN and Liq were employed as the hole and electron-injection materials, respectively; TAPC and TmPyPB served as the hole-transporting layer and electron-transporting layer; emitter doped in DPEPO host utilized as the emitting layer (EML); TCTA was used as the exciton blocking layer, and the high $\mathrm{T}_{1}$ of $m \mathrm{CP}$ and DPEPO can confine triplet excitons within the EMLs. Figure 3 shows the performances of the vacuum-deposited OLEDs based on 2tDMG and 3tDMG and the EL maximum peaks are 504 and $518 \mathrm{~nm}$ respectively, agreeing well with their photoluminescence behaviors. The best EL efficiency is found with 2tDMG (device 1: 30.8\%, $88.5 \mathrm{~cd} / \mathrm{A}, 71.8 \mathrm{~lm} / \mathrm{W}$ ) whereas 3tDMG displays lower performance (device 2: 26.3\%, 85.0 cd/A, $73.9 \mathrm{~lm} / \mathrm{W}$ ) and both devices show a small roll-off. 2tDMG has much shorter D/A distance, meanwhile, the fit planes of donor and acceptor are near to parallel which is beneficial for space charge transfer. Then, we also designed devices 3 and 4 , in which $m \mathrm{CP}$ was used as host instead of DPEPO, device structure: ITO/ HAT-CN (10 nm)/ TAPC (40 $\mathrm{nm}) /$ TCTA $(8 \mathrm{~nm}) / m \mathrm{CP}$ : emitters $(20 \mathrm{~nm}, 30 \mathrm{wt} \%$ for 2tDMG, $20 \mathrm{wt} \%$ for 3tDMG)/ 


\section{WILEY-VCH}

TmPyPB $(40 \mathrm{~nm}) / \mathrm{Liq}(2 \mathrm{~nm}) / \mathrm{Al}(100 \mathrm{~nm})$. However, the EL efficiencies of 2tDMG and 3tDMG were lower than those using DPEPO. Actually, it is believed that n-type hosts, such as DPEPO, are suitable to realize stable delayed fluorescence organic electroluminescent devices. $^{[22]}$

Because of the $t$-butyl groups, 2tDMG and 3tDMG have the potential for solution-processed OLEDs. Therefore, we fabricated solution-processed OLEDs (Device 5-6) as shown in Figure 3, and the best structure was: ITO/ poly(3,4-ethylenedioxythiophene)-poly(styrene sulfonate) (PEDOT:PSS, $40 \mathrm{~nm}) /$ 10-(4-(4-(9H-carbazol-9-yl)phenylsulfonyl)phenyl)-9,9dimethyl-9,10-dihydroacridine (CzAcSF): 10 wt\% emitters (40 nm)/ DPEPO (10 nm)/ TmPyPB $(50 \mathrm{~nm}) / \mathrm{Liq}(1 \mathrm{~nm}) / \mathrm{Al}(100 \mathrm{~nm})$. In these devices, PEDOT:PSS and Liq acted as the hole-injection layer and electron-injection layer respectively, TmPyPB served as the electron-transporting layer, and CzAcSF was selected as the host. DPEPO was used as the hole-blocking layer to optimize the devices (Supporting Information, Figure S16, S17). These solution-processed OLEDs show blue-shift EL emission peaks, 486 (2tDMG) and 504 nm (3tDMG), compared to the vacuum-processed devices. Moreover, these solution-processed OLEDs achieve competitive high efficiencies with maximum EQEs of 16.2\% (2tDMG) and 20.2\% (3tDMG). It is believed that the better solubility of 3tDMG than 2tDMG due the presence of two $t$-butyl groups is one of the reasons of its better device performance in solution process OLEDs (Figure S18). To our best knowledge, this is also the first time reaching $20 \%$ EQE threshold out of the traditional D- $\pi$-A TADF series. ${ }^{[7 \mathrm{a}, 7 \mathrm{c}, 23]}$ All the device performances of 2tDMG and 3tDMG are summarized in Table 2.

In summary, we designed and synthesized greenish-blue TADF emitters based unconjugated D/A blocks interacted in confined space. These materials rely on the rigid backbone and short $\mathrm{D} / \mathrm{A}$ distance which in turn restrict the free rotations of constitutional blocks and impose D/A 


\section{WILEY-VCH}

to adopt a favorable cofacial conformation. t-butyl groups are introduced to make the TADF emitters 2tDMG and 3tDMG suitable for both evaporation and solution processed devices. As a result, both materials show small $\Delta E_{\mathrm{ST}}$ and high PLQY as well as high $T_{\mathrm{g}}$ because of the rigid backbone. In evaporation-processed TADF devices, 2tDMG and 3tDMG achieve 30.8\% and $26.3 \%$ EQEs respectively; notably, the efficiency can retain as high as $28.5 \%$ and $23.2 \%$ at the $1000 \mathrm{~cd} / \mathrm{m}^{2}$ respectively, indicating very flat efficiency roll-offs. In solution-processed OLEDs, the maximum EQEs are $16.2 \%$ and $20.2 \%$ for 2tDMG and 3tDMG respectively. These excellent performances clearly demonstrate a disruptive motif in constructing highly efficient TADF materials out of conventional D- $\pi-\mathrm{A}$ architecture. We thus believe our results could shed a new light on the development of optoelectronic functional materials in noncovalent interactions.

[CCDC-1992381 (2tDMG) and CCDC-1992382 (3tDMG) contains the supplementary crystallographic data for this paper. These data can be obtained free of charge from The Cambridge Crystallographic Data Centre via www.ccdc.cam.ac.uk/data_request/cif.]

\section{Supporting Information}

Supporting Information is available from the Wiley Online Library or from the author.

\section{Acknowledgements}

The authors acknowledge financial support from the National Key R\&D Program of China (No. 2016YFB0400700), the National Natural Science Foundation of China (Nos. 51773141, 51873139 and 21572152) and the Natural Science Foundation of Jiangsu Province of China (BK20181442). This project is also funded by Collaborative Innovation Centre of Suzhou Nano Science \& Technology, the Priority Academic Program Development of Jiangsu Higher Education Institutions (PAPD), the 111 Project of The State Administration of Foreign Experts Affairs of China. 


\section{WILEY-VCH}

Received: ((will be filled in by the editorial staff))

Revised: ((will be filled in by the editorial staff))

Published online: ((will be filled in by the editorial staff))

\section{References}

[1] a) H. Uoyama, K. Goushi, K. Shizu, H. Nomura, C. Adachi, Nature 2012, 492, 234; b) Y. Im, M. Kim, Y. J. Cho, J.-A. Seo, K. S. Yook, J. Y. Lee, Chem. Mater. 2017, 29, 1946; c) M. Y. Wong, E. Zysman-Colman, Adv. Mater. 2017, 29, 1605444; d) Z. Yang, Z. Mao, Z. Xie, Y. Zhang, S. Liu, J. Zhao, J. Xu, Z. Chi, M. P. Aldred, Chem. Soc. Rev. 2017, 46, 915; e) Y. Yuan, Y. Hu, Y.-X. Zhang, J.-D. Lin, Y.-K. Wang, Z.-Q. Jiang, L.-S. Liao, S.-T. Lee, Adv. Funct. Mater. 2017, 27, 1700986.

[2] a) T. A. Lin, T. Chatterjee, W. L. Tsai, W. K. Lee, M. J. Wu, M. Jiao, K. C. Pan, C. L. Yi, C. L. Chung, K. T. Wong, C. C. Wu, Adv. Mater. 2016, 28, 6976; b) W. Zeng, H.-Y. Lai, W.K. Lee, M. Jiao, Y.-J. Shiu, C. Zhong, S. Gong, T. Zhou, G. Xie, M. Sarma, K.-T. Wong, C.C. Wu, C. Yang, Adv. Mater. 2018, 30, 1704961; c) T.-L. Wu, M.-J. Huang, C.-C. Lin, P.-Y. Huang, T.-Y. Chou, R.-W. Chen-Cheng, H.-W. Lin, R.-S. Liu, C.-H. Cheng, Nat. Photonics 2018, 12, 235; d) D. H. Ahn, S. W. Kim, H. Lee, I. J. Ko, D. Karthik, J. Y. Lee, J. H. Kwon, Nat. Photonics 2019, 13, 540; e) L.-S. Cui, A. J. Gillett, S.-F. Zhang, H. Ye, Y. Liu, X.-K. Chen, Z.-S. Lin, E. W. Evans, W. K. Myers, T. K. Ronson, H. Nakanotani, S. Reineke, J.-L. Bredas, C. Adachi, R. H. Friend, Nat. Photonics. 2020, DOI: 10.1038/s41566-020-0668-z.

[3] a) P. Rajamalli, N. Senthilkumar, P. Gandeepan, P.-Y. Huang, M.-J. Huang, C.-Z. Ren-Wu, C.-Y. Yang, M.-J. Chiu, L.-K. Chu, H.-W. Lin, C.-H. Cheng, J. Am. Chem. Soc. 2016, 138, 628; b) P. Rajamalli, N. Senthilkumar, P. Y. Huang, C. C. Ren-Wu, H. W. Lin, C. H. Cheng, J. Am. Chem. Soc. 2017, 139, 10948; c) L.-S. Cui, H. Nomura, Y. Geng, J. U. Kim, H. Nakanotani, C. Adachi, Angew. Chem., Int. Ed. 2017, 56, 1571.

[4] S. Hirata, Y. Sakai, K. Masui, H. Tanaka, S. Y. Lee, H. Nomura, N. Nakamura, M. 


\section{WILEY-VCH}

Yasumatsu, H. Nakanotani, Q. Zhang, K. Shizu, H. Miyazaki, C. Adachi, Nat. Mater. 2015, 14, 330.

[5] a) J. Guo, Z. Zhao, B. Z. Tang, Adv. Opt. Mater. 2018, 6, 1800264; b) J. Sun, J. Zhang, Q.

Liang, Y. Wei, C. Duan, C. Han, H. Xu, Adv. Funct. Mater. 2020, 30, 1908568.

[6] a) K. Goushi, K. Yoshida, K. Sato, C. Adachi, Nat. Photonics 2012, 6, 253; b) M. Colella, P. Pander, D. d. S. Pereira, A. P. Monkman, ACS Appl. Mater. Interfaces 2018, 10, 40001; c) T.-C. Lin, M. Sarma, Y.-T. Chen, S.-H. Liu, K.-T. Lin, P.-Y. Chiang, W.-T. Chuang, Y.-C. Liu, H.-F. Hsu, W.-Y. Hung, W.-C. Tang, K.-T. Wong, P.-T. Chou, Nat. Commun. 2018, 9, 3111; d) M. Sarma, K. T. Wong, ACS Appl. Mater. Interfaces 2018, 10, 19279; e) M. Chapran, P. Pander, M. Vasylieva, G. Wiosna-Salyga, J. Ulanski, F. B. Dias, P. Data, ACS Appl. Mater. Interfaces 2019, 11, 13460; f) T. B. Nguyen, H. Nakanotani, T. Hatakeyama, C. Adachi, Adv. Mater. 2020, 32, 1906614.

[7] a) S. Shao, J. Hu, X. Wang, L. Wang, X. Jing, F. Wang, J. Am. Chem. Soc. 2017, 139, 17739; b) H. Tsujimoto, D.-G. Ha, G. Markopoulos, H. S. Chae, M. A. Baldo, T. M. Swager, J. Am. Chem. Soc. 2017, 139, 4894; c) J. Hu, Q. Li, X. Wang, S. Shao, L. Wang, X. Jing, F. Wang, Angew. Chem., Int. Ed. 2019, 58, 8405; d) J. Li, P. Shen, Z. Zhao, B. Z. Tang, CCS Chem. 2019, 1, 181; e) J.-A. Lin, S.-W. Li, Z.-Y. Liu, D.-G. Chen, C.-Y. Huang, Y.-C. Wei, Y.-Y. Chen, Z.-H. Tsai, C.-Y. Lo, W.-Y. Hung, K.-T. Wong, P.-T. Chou, Chem. Mater. 2019, 31, 5981; f) K.-L. Woon, C.-L. Yi, K.-C. Pan, M. K. Etherington, C.-C. Wu, K.-T. Wong, A. P. Monkman, J. Phys. Chem. C 2019, 123, 12400; g) Q. Li, J. Hu, J. Lv, X. Wang, S. Shao, L. Wang, X. Jing, F. Wang, Angew. Chem., Int. Ed. 2020, doi:10.1002/anie.202008912.

[8] K. Kawasumi, T. Wu, T. Zhu, H. S. Chae, T. Van Voorhis, M. A. Baldo, T. M. Swager, J. Am. Chem. Soc. 2015, 137, 11908.

[9] a) M. Li, Y.-F. Wang, D. Zhang, L. Duan, C.-F. Chen, Angew. Chem., Int. Ed. 2020, 59, 3500; b) T. Wang, K. Li, B. Yao, Y. Chen, H. Zhan, Z. Xie, G. Xie, X. Yi, Y. Cheng, Adv. 


\section{WILEY-VCH}

Funct. Mater. 2020, 2002493; c) D. Ding, Z. Wang, C. Li, J. Zhang, C. Duan, Y. Wei, H. Xu, Adv. Mater. 2020, 32, 1906950.

[10] a) X. Tang, L.-S. Cui, H.-C. Li, A. J. Gillett, F. Auras, Y.-K. Qu, C. Zhong, S. T. E. Jones, Z.-Q. Jiang, R. H. Friend, L.-S. Liao, Nat. Mater. 2020, DOI: 10.1038/s41563-0200710-z; b) Y. Wada, H. Nakagawa, S. Matsumoto, Y. Wakisaka, H. Kaji, Nat. Photonics 2020, DOI: $10.1038 / \mathrm{s} 41566-020-0667-0$.

[11] L. J. Sicard, H.-C. Li, Q. Wang, X.-Y. Liu, O. Jeannin, J. Rault-Berthelot, L.-S. Liao, Z.Q. Jiang, C. Poriel, Angew. Chem., Int. Ed. 2019, 58, 3848.

[12] a) J.-Y. Hu, Y.-J. Pu, Y. Yamashita, F. Satoh, S. Kawata, H. Katagiri, H. Sasabe, J. Kido, J. Mater. Chem. C 2013, 1, 3871; b) J. Li, Y.-H. Li, Y. Zhao, X.-Y. Liu, M.-K. Fung, J. Fan, Org. Electron. 2018, 54, 140.

[13] L. Sicard, C. Quinton, F. Lucas, O. Jeannin, J. Rault-Berthelot, C. Poriel, J. Phys. Chem. Lett. 2019, 123, 19094.

[14] Donald J. Cram, Jane M. Cram, Acc. Chem. Res. 1971, 4, 204.

[15] P. J. Stephens, F.J. Devlin, C.F. Chabalowski, M.J. Frisch, J. Phys. Chem. 1994, 98,11623-11627.

[16] S. Grimme, S. Ehrlich, L. Goerigk, J. Comput. Chem. 2011, 32, 1456-1465.

[17] Grimme, S., Ehrlich, S. \& Goerigk, L. J. Comput. Chem. 2011, 32, 1456-1465.

[18] F. Weigend, R. Ahlrichs, Phys. Chem. Chem. Phys. 2005, 7, 3297-3305.

[19] T. Lu, F. Chen, J. Comput. Chem. 2012, 33, 580-592.

[20] a) Z. Mao, Z. Yang, C. Xu, Z. Xie, L. Jiang, F. L. Gu, J. Zhao, Y. Zhang, M. P. Aldred, Z. Chi, Chem. Sci. 2019, 10, 7352; b) Z. Yang, Z. Mao, C. Xu, X. Chen, J. Zhao, Z. Yang, Y. Zhang, W. Wu, S. Jiao, Y. Liu, M. P. Aldred, Z. Chi, Chem. Sci. 2019, 10, 8129.

[21] F. Lucas, O. A. Ibraikulov, C. Quinton, L. Sicard, T. Heiser, D. Tondelier, B. Geffroy, N. Leclerc, J. Rault-Berthelot, C. Poriel, Adv. Opt. Mater. 2020, 8, 1901225. 


\section{WILEY-VCH}

[22] L.-S. Cui, S.-B. Ruan, F. Bencheikh, R. Nagata, L. Zhang, K. Inada, H. Nakanotani, L.-S.

Liao, C. Adachi, Nat. Commun. 2017, 8, 2250.

[23] Z. Yang, Z. Mao, Z. Xie, Y. Zhang, S. Liu, J. Zhao, J. Xu, Z. Chi, M. P. Aldred, Chem. Soc. Rev. 2017, 46, 915.

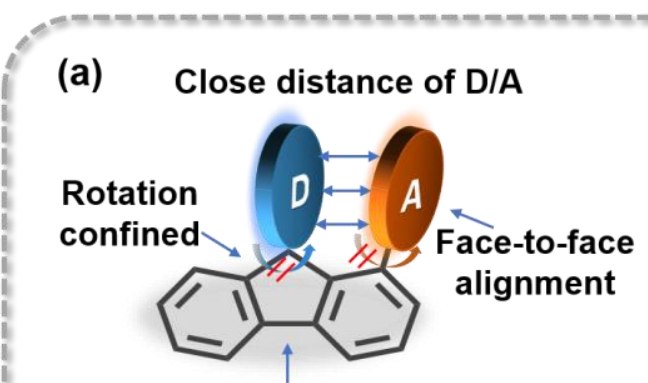

Rigid linker

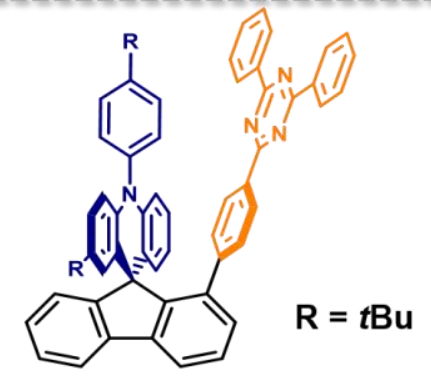

2tDMG

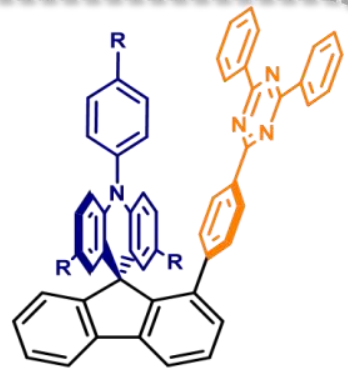

3tDMG

(b)

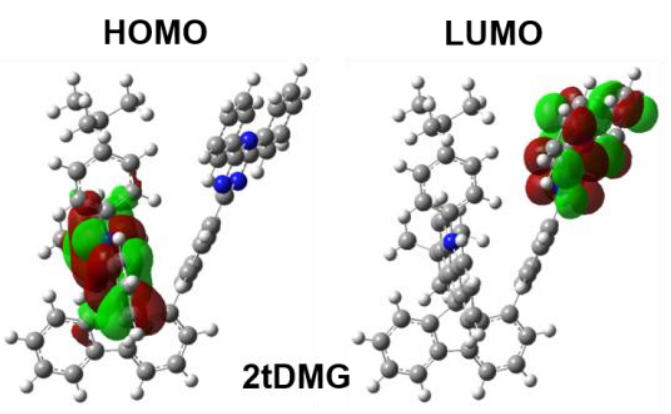

(c) HOMO

LUMO

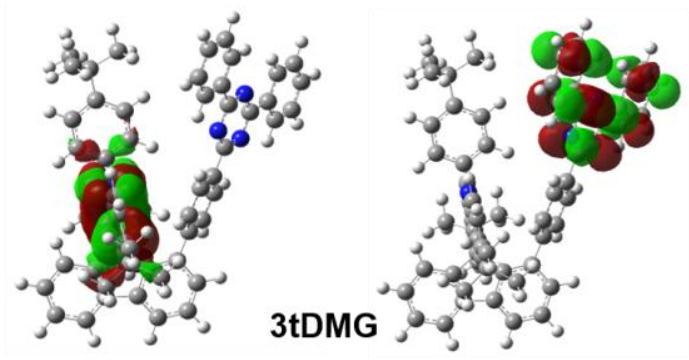

(d)
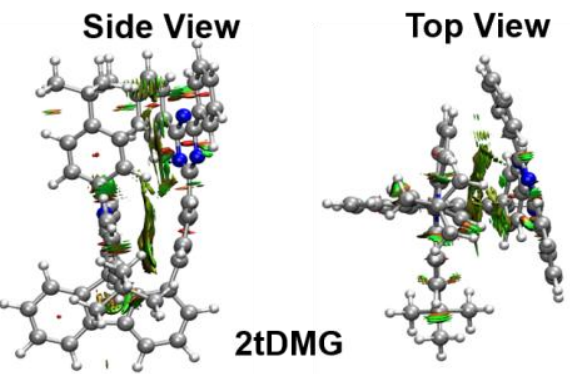

(f)

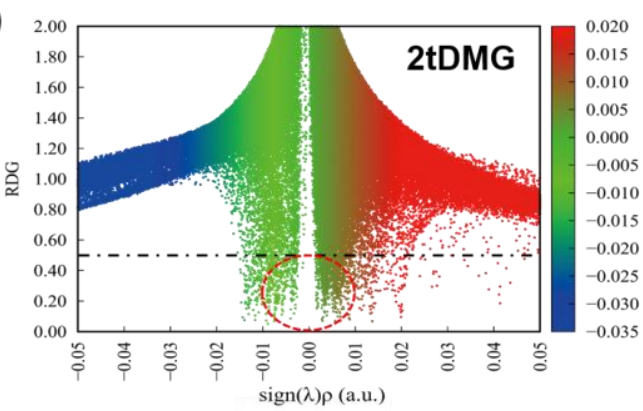

(e)
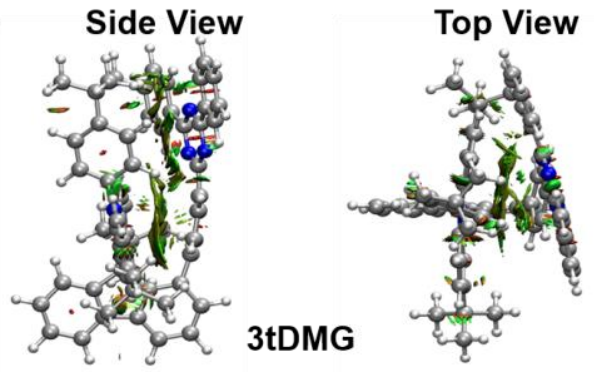

(g)

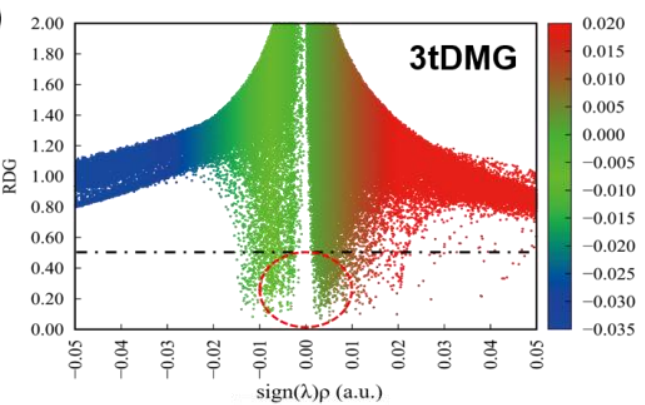

Figure 1. Configuration and molecular structures (a) of 2tDMG and 3tDMG; HOMO and LUMO orbital distributions of (b) 2tDMG and (c) 3tDMG. Reduced density gradient (RDG) 


\section{WILEY-VCH}

isosurface map with an isovalue of 0.5 for (d) 2tDMG and (e) 3tDMG. The functions of RDG and Sign $\left(\lambda_{2}\right) \rho$ for (f) 2tDMG and (g) 3tDMG.

(a)

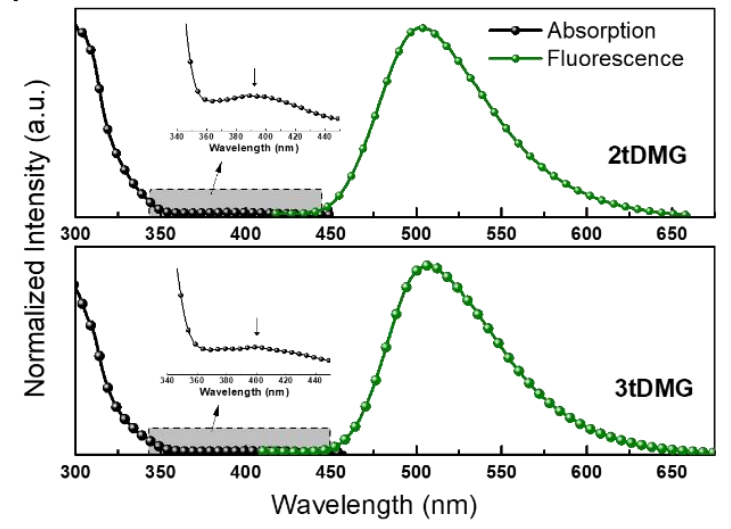

(b)

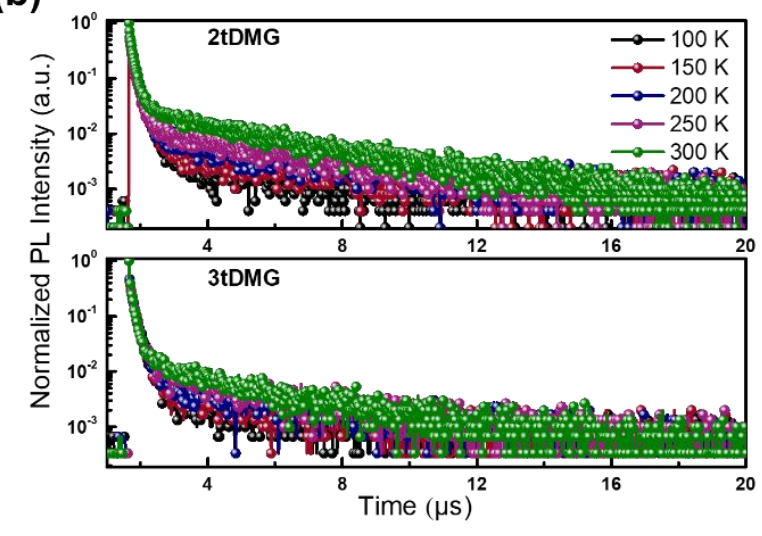

Figure 2. (a) UV-vis absorption, fluorescence (298 K) of 2tDMG and 3tDMG respectively.

(b) Temperature-dependent PL decay curves from 300 to $100 \mathrm{~K}$ of 2tDMG (40 wt $\%$ ) and 3tDMG (40 wt\%) doped in DPEPO film respectively.
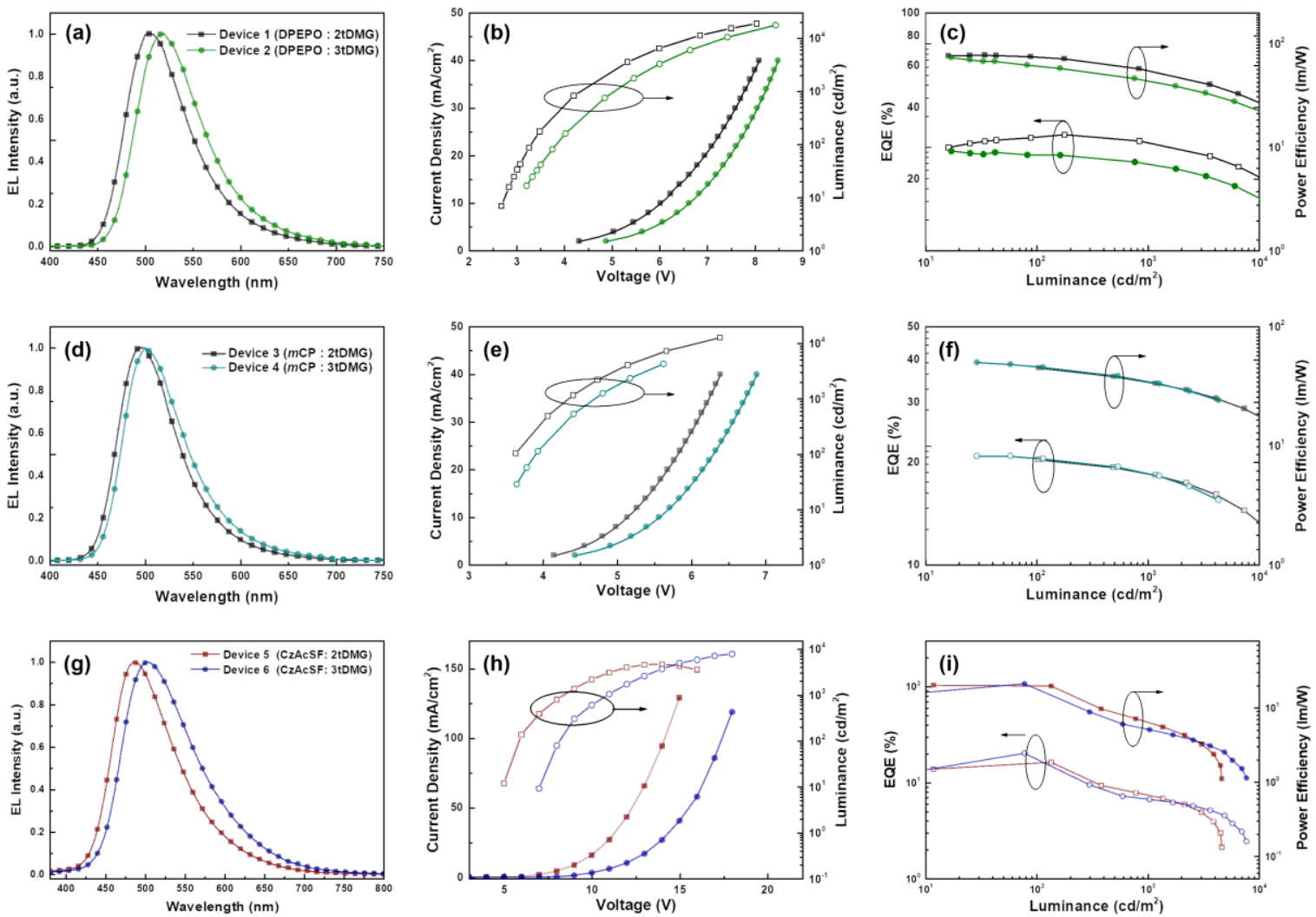


\section{WILEY-VCH}

Figure 3. OLED device performances based on different device structures (Device 1-6). (a, d, g) EL spectra curves; (b, e, h) current density to voltage to luminance $(J-V-L)$ curves; (c, f, i) EQE to luminance curves and power efficiency (PE) to luminance curves.

Table 1. Summary of photophysical, electrochemical and thermal properties of 2tDMG and 3tDMG.

\begin{tabular}{llllllllll}
\hline \multirow{2}{*}{ Compounds } & $\begin{array}{l}\lambda_{\text {abs }}{ }^{\text {a) }} \\
{[\mathrm{nm}]}\end{array}$ & $\begin{array}{l}\lambda_{\mathrm{em}}{ }^{\mathrm{a})} \\
{[\mathrm{nm}]}\end{array}$ & $\begin{array}{l}\mathrm{S}_{1}{ }^{\mathrm{b})} \\
{[\mathrm{eV}]}\end{array}$ & $\begin{array}{l}\mathrm{T}_{1}{ }^{\mathrm{b})} \\
{[\mathrm{eV}]}\end{array}$ & $\begin{array}{l}\Delta E_{\mathrm{ST}} \\
{[\mathrm{eV}]}\end{array}$ & $\begin{array}{l}\mathrm{HOMO}^{\mathrm{c})} \\
{[\mathrm{eV}]}\end{array}$ & $\begin{array}{l}\mathrm{LUMO}^{\mathrm{c})} \\
{[\mathrm{eV}]}\end{array}$ & $\begin{array}{l}T_{\mathrm{g}}{ }^{\mathrm{d})} \\
{\left[{ }^{\circ} \mathrm{C}\right]}\end{array}$ & $\begin{array}{l}T_{\mathrm{d}}{ }^{\mathrm{e})} \\
{\left[{ }^{\circ} \mathrm{C}\right]}\end{array}$ \\
\hline 2tDMG & 297,389 & 502 & 2.96 & 2.93 & 0.03 & -5.12 & -2.37 & 165 & 369 \\
3tDMG & 289,403 & 505 & 2.91 & 2.90 & 0.01 & -5.03 & -2.37 & 154 \\
\hline
\end{tabular}

a) In toluene $\left(10^{-5} \mathrm{M}\right)$ solution at room temperature; ${ }^{\text {b) }}$ determined from the fluorescence and phosphorescence spectrum measured in toluene solution at $77 \mathrm{~K} .{ }^{c}$ estimated from the redox potential in cyclic voltammetry; ${ }^{\text {d) }} T_{\mathrm{g}}$ obtained from DSC measurements; ${ }^{\text {e) }} T_{\mathrm{d}}$ obtained from TGA measurements.

Table 2. Summary of device performances utilizing 2tDMG and 3tDMG.

\begin{tabular}{|c|c|c|c|c|c|c|c|}
\hline Device & Process & Host: Dopant & $\begin{array}{c}\mathrm{EL} \\
{[\mathrm{nm}]}\end{array}$ & $\begin{array}{c}\mathrm{EQE}^{\mathrm{a})} \\
{[\%]}\end{array}$ & $\begin{array}{c}\mathrm{PE}^{\mathrm{a})} \\
{[\mathrm{lm} / \mathrm{W}]}\end{array}$ & $\begin{array}{c}\mathrm{CE}^{\mathrm{a})} \\
{[\mathrm{cd} / \mathrm{A}]}\end{array}$ & $\begin{array}{c}\mathrm{CIE} \\
{[\mathrm{x}, \mathrm{y}]}\end{array}$ \\
\hline 1 & evaporation & DPEPO: $2 \mathrm{tDMG}$ & 504 & $30.8,28.5,24.6$ & $71.8,55.5,38.8$ & $88.5,81.9,70.3$ & $(0.24,0.53)$ \\
\hline 2 & evaporation & DPEPO: 3tDMG & 518 & $26.3,23.2,20.1$ & $73.9,44.3,31.5$ & $85.0,74.3,64.2$ & $(0.29,0.57)$ \\
\hline 3 & evaporation & $m \mathrm{CP}: 2 \mathrm{tDMG}$ & 496 & $20.4,18.5,16.1$ & $50.1,34.0,25.2$ & $52.0,47.3,41.2$ & $(0.20,0.46)$ \\
\hline 4 & evaporation & $m \mathrm{CP}: 3 \mathrm{tDMG}$ & 501 & $20.8,18.4,15.6$ & $45.0,32.7,24.4$ & $58.0,51.8,43.8$ & $(0.24,0.52)$ \\
\hline 5 & solution & CzAcSF: 2tDMG & 486 & $16.2,7.4,3.6$ & $20.1,6.4,2.4$ & $37.5,17.2, /$ & $(0.22,0.37)$ \\
\hline 6 & solution & CzAcSF: $3 \mathrm{tDMG}$ & 504 & $20.1,6.7,4.9$ & $21.1,5.1,2.9$ & $53.6,17.9,12.0$ & $(0.28,0.46)$ \\
\hline
\end{tabular}

(CE) at the maximum, $1000 \mathrm{~cd} / \mathrm{m}^{2}$, and $4000 \mathrm{~cd} / \mathrm{m}^{2}$, respectively. 


\section{WILEY-VCH}

The table of contents entry: The thermally activated delayed fluorescence emitter $2 \mathrm{tDMG}$ is designed and synthesized based on donor (D)/acceptor (A) spatially intramolecular noncovalent interaction. The D/A units are connected via a rigid linker, thereby confining them into a close-packed coplanar configuration for small singlet-triplet splitting energy $\left(\Delta E_{\mathrm{ST}}\right) .2 \mathrm{tDMG}$ achieves a high external quantum efficiency of $30.8 \%$ with a low efficiency roll-off in evaporation-processed.

Keyword: thermally activated delayed fluorescence; organic light-emitting diodes; high efficiency; intramolecular spatial charge transfer; spiro structure

C.-C. Peng, S.-Y. Yang, H.-C. Li, G.-H. Xie, L.-S. Cui, S.-N. Zou, C. Poriel, Z.-Q. Jiang*, L.S. Liao*

High Performance Organic Light Emitting Diode with over 30\% External Quantum Efficiency by Using Thermally Activated Delayed Fluorescence

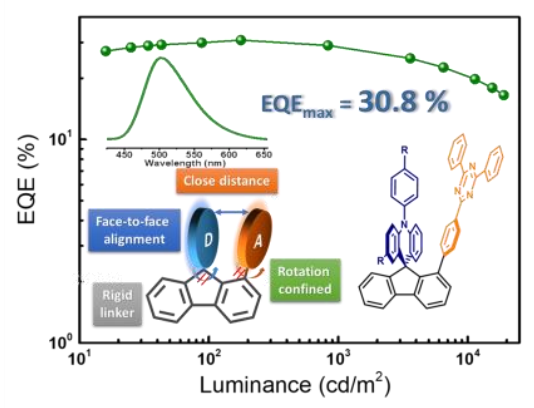

